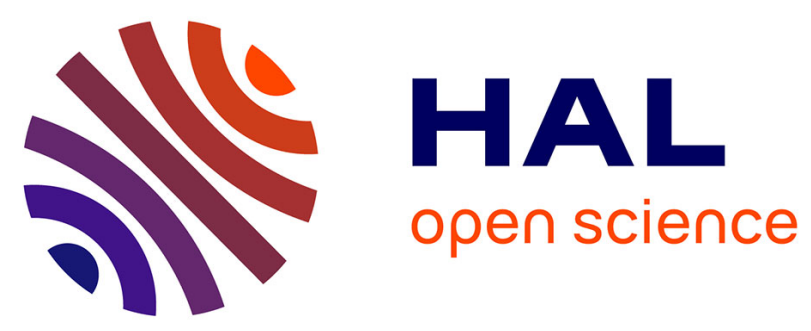

\title{
Crystal and molecular structure of 1-picryl-2-phenyl-2-(4-picrylamidophenyl)-diazenium betaine: analogy between a picramido group and an oxygen atom
}

Alexandru Balaban, Titus Constantinescu, Miron Teodor Caproiu, Michel Giorgi, Teodor Silviu Balaban

\section{To cite this version:}

Alexandru Balaban, Titus Constantinescu, Miron Teodor Caproiu, Michel Giorgi, Teodor Silviu Balaban. Crystal and molecular structure of 1-picryl-2-phenyl-2-(4-picrylamidophenyl)-diazenium betaine: analogy between a picramido group and an oxygen atom. Zeitschrift fur Naturforschung B, 2017, 72 (2), 10.1515/znb-2016-0194 . hal-01683279

\section{HAL Id: hal-01683279 https://hal.science/hal-01683279}

Submitted on 16 Apr 2018

HAL is a multi-disciplinary open access archive for the deposit and dissemination of scientific research documents, whether they are published or not. The documents may come from teaching and research institutions in France or abroad, or from public or private research centers.
L'archive ouverte pluridisciplinaire HAL, est destinée au dépôt et à la diffusion de documents scientifiques de niveau recherche, publiés ou non, émanant des établissements d'enseignement et de recherche français ou étrangers, des laboratoires publics ou privés. 


\section{Crystal and molecular structure of 1-picryl-2-phenyl- 2-(4-picrylamidophenyl)-diazenium betaine: analogy between a picramido group and an oxygen atom}

\begin{abstract}
The title compound is formed by a non-trivial reaction involving two molecules of the stable free radical 2,2-diphenyl-1-picryl-hydrazyl and one molecule of $N$-methoxy-picramide. We could now perform an X-ray diffraction experiment on a single crystal and can fully confirm the betaine structure which has a central quinonoid ring with alternating long and short bonds.
\end{abstract}

Keywords: crystal structure; DPPH; push-pull aminyls; stable free radicals.

\section{Introduction}

Since its synthesis by Stefan Goldschmidt in 1922 [1], 2,2-diphenyl-1-picryl-hydrazyl (DPPH, 1) has proven to be one of the most stable free radicals. Due to its intense violet color, it has been frequently used as a reagent for analytical chemistry and it has also been used as a standard compound for electron paramagnetic resonance (EPR) spectroscopy. Its molecular structure was investigated repeatedly [2-4].

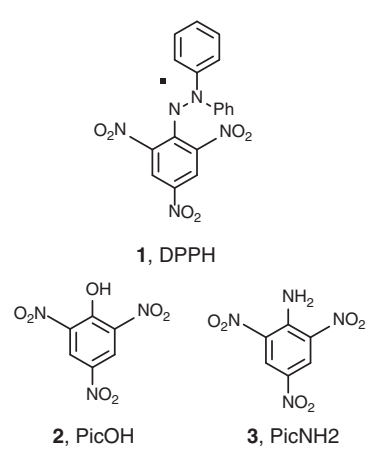

We shall use the shorter name picryl (abbreviated as Pic) for the 2,4,6-trinitrophenyl residue. Accordingly, as 2,4,6-trinitrophenol (2) is termed picric acid due to its extraordinary acidity for a phenol, we shall use the name picramide for the corresponding 2,4,6-trinitroaniline (3). Having obtained from two molar equivalents of DPPH and one molar equivalent of $\mathrm{N}$-alkoxy-picramide (4), a deepblue crystalline compound, we assigned it the structure of 1-picryl-2-phenyl-2-(4-picramidophenyl)-diazenium betaine (6) on the basis of physical and chemical redox properties [5]. We now confirm here, almost after two decades, the intriguing structure of betaine 6 by single crystal X-ray diffraction. From this molecular structure we prove that the quinonoid form $\mathbf{6 a}$ shown is dominant.
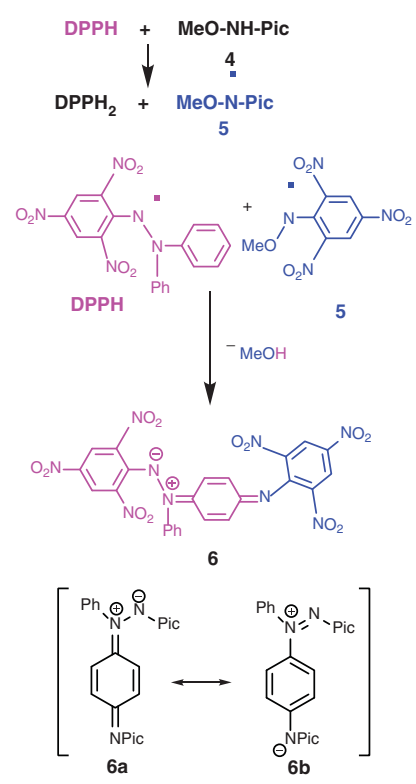

\footnotetext{
* Corresponding author: Alexandru T. Balaban, Department of Marine Sciences, Texas A\&M University at Galveston, 200 Seawolf Parkway, Galveston, TX 77553, USA, e-mail: balabana@tamu.edu Titus Constantinescu: Romanian Academy, "llie Murgulescu” Institute of Physical Chemistry, 060021 Bucharest, Romania Miron Teodor Caproiu: Romanian Academy, “Costin D. Nenitzescu” Center of Organic Chemistry, 060023 Bucharest, Romania Michel Giorgi: Aix-Marseille University, CNRS FR 1739, Spectropole, F-13397 Marseille CEDEX 20, France

Teodor Silviu Balaban: Aix-Marseille University, CNRS, Centrale Marseille, Institut des Sciences Moléculaires de Marseille (iSm2), UMR 7313, Chirosciences, F-13397 Marseille CEDEX 20, France
} 
In the reaction described above, one equivalent of $\mathrm{DPPH}$ is used to convert the $N$-alkoxy-picramide (4) into the stable free radical $N$-alkoxy-picrylaminyl (5), which then eliminates the alkoxy group and combines with DPPH forming the betaine $\mathbf{6}$. The intermediate radical 5 is also fairly persistent and could be characterized by EPR spectroscopy [6]. Formally, a picramido group (Pic-N) replaces the para-hydrogen of the syn-phenyl in DPPH yielding the quinonoid ring of $\mathbf{6}$. This radical transformation is unusual and nontrivial, which has led to uncertainties in its mechanism in the absence of the definitive structural proof of the blue betainic reaction product 6 .

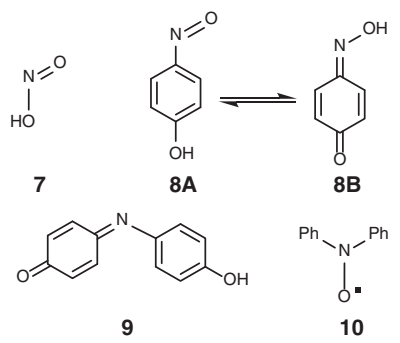

The notion of phenylogy is illustrated by going first from nitrous acid (7) to the tautomeric pair of para-nitrosophenol (8A) and para-benzoquinone oxime (8B), ${ }^{1}$ and then finally to indophenol (9). Compounds 7 and 9 undergo degenerate tautomerism due to their oxygen-symmetric structures. With its high electronegativity, an oxygen atom is analogous to a picramido group; hence one can also envisage DPPH as a "picramido-homolog" of $\mathrm{N}, \mathrm{N}$-diphenylnitroxide (10), in which the oxygen atom is replaced by a picramido group. Compounds 11-13 illustrate the analogy of a picramido group and an oxygen atom. We reported earlier the betaine $\mathbf{1 2}$ [7], but its isomer $\mathbf{1 3}$ is unknown.

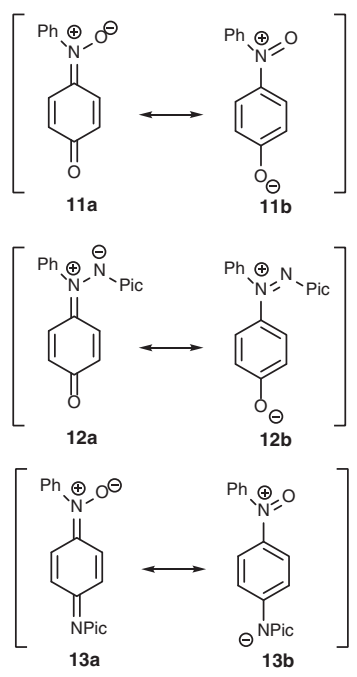

1 We denote by capital letters tautomers or conformers which can be differently populated. Mesomeric (resonance) structures are labeled by lower script letters.
Actually, DPPH and other stable hydrazyls are just push-pull aminyls: DPPH has a diphenylamino electrondonor group and an electron-acceptor picryl group. Shortly after the idea of push-pull stabilization of nitrogen-centered free radicals was introduced [8], new names for this effect were proposed by Viehe et al. (capto-dative stabilization) [9], and Katritzky et al. (merostabilization) [10]. These authors tried to extend their views to carboncentered free radicals, but in such cases the effects are weaker because conjugation involving $\sigma$ electrons is less effective than when involving unshared or $\pi$ electrons. The push-pull stabilization of aminyls is easily explained by Linnett's theory that postulates all atoms of aminyl free radicals to have electron octets by taking into account the $\alpha$ and $\beta$ electron spins [11, 12], as shown in the bottom formula of DPPH in Fig. 1. Among the two phenyl groups of DPPH, the group in anti orientation to the picryl group has a higher spin density than the group in syn orientation (see the third of the top resonance structures in Fig. 1). A consequence of this theory is a three-electron $\mathrm{N}-\mathrm{N}$ bond in hydrazyls, as shown by X-ray crystallography of DPPH [4], and a higher rotation barrier around the N-N bond, as proved experimentally by variable-temperature EPR spectroscopy [13].

\section{Results and discussion}

By repeated thin-layer chromatographic purifications and a final recrystallization from toluene, the betainic compound 6 was obtained in fine needle-like crystals with metallic luster which were suitable for X-ray diffractometry. Their color varies with the light's incidence angle appearing either as dark blue or green-nacre with a copper reflex. Figure 2 presents the molecular structure together with a few interatomic distances. The para-phenylene

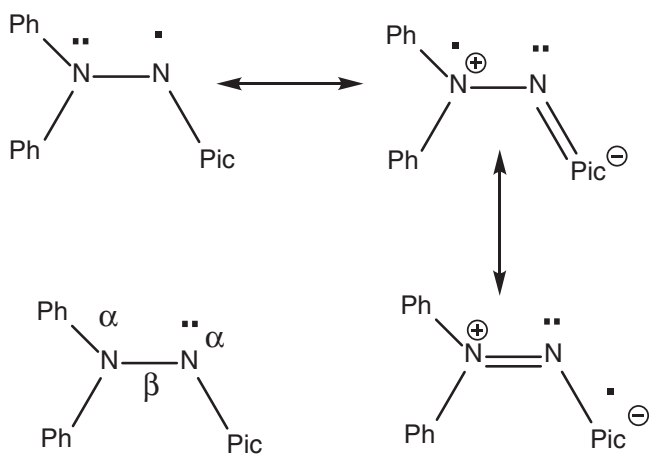

Fig. 1: Resonance structures of DPPH and Linnett's formulation of DPPH (lower row at left). 


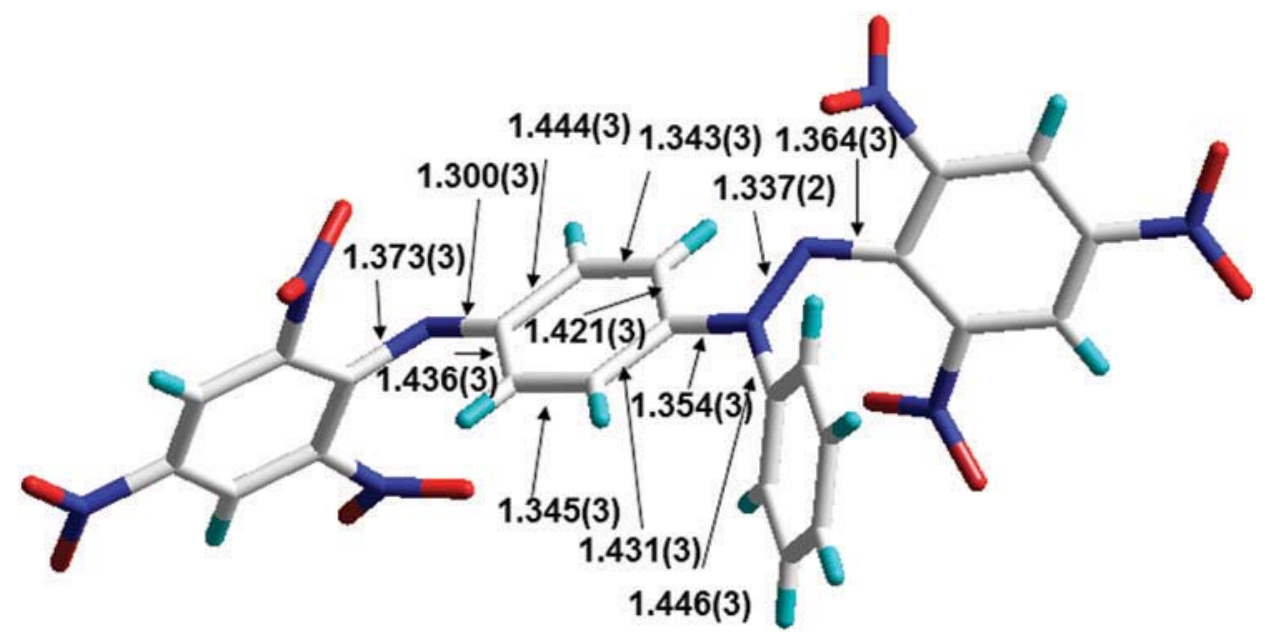

Fig. 2: Molecular structure of the betainic compound 6 in the crystal with bond lengths indicated in $\AA$. All hydrogen atoms are shown.

group has a distinct quinonoid structure with shorter

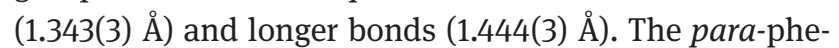
nylenic $\mathrm{C}=\mathrm{N}$ bonds are also short (1.354(3) and 1.300(3) $\AA$ ).

The $\mathrm{N}-\mathrm{N}$ bond length $(1.337(2) \AA)$ is comparable to that observed for DPPH $[2,4]$. The $\mathrm{C}-\mathrm{N}$ bond lengths differ markedly: both picryl-N bonds are rather short with approximately $1.37 \AA$, but as expected, the $\mathrm{C}-\mathrm{N}$ bond length for the phenyl-N bond (1.446(3) $\AA$ ) indicates clearly a single bond.

Sharp bond angles at the diarylaminic nitrogens create U-type bay regions that intermesh pairwise with $\pi-\pi$ intermolecular interactions between picryl groups with atom-to-atom distances as short as $3.39 \AA$, flanked by two external phenyl groups. It is remarkable that even after two decades, the crystals still retained their crystallization solvent, toluene, which is disordered in the lattice over two centrosymmetric positions. Table 1 summarizes the crystallographic details and the structure refinement.

It is noteworthy that of the four possible conformations taking into account the $E / Z$ configuration of the $\mathrm{N}=\mathrm{N}$ bond (in structure $6 \mathbf{b}$ ) and of the syn/anti orientation of the picryl group, the crystal structure shows an E-anti conformer which could be stabilized by the crystal packing forces.

We tried to get insight into the stabilities of these four conformers by performing semi-empirical PM3 calculations [14]. Figure 3 shows the four computed geometries which are all within $<1 \mathrm{kcal} \mathrm{mol}^{-1}$ in energy apart, and thus within the error limits inherent to this method. However, an overlay of the computed geometry for $6 \mathrm{D}$ is in a quite good agreement with that encountered in the crystal as shown at right in Fig. 3. Especially well reproduced are the bond lengths of the central quinonoidal ring, which is the main feature of this compound and which accounts for its intense blue color.
Using the same computational approach we calculated the ground-state dipole moments of $\mathbf{6}$ and of the picramido groups replaced by oxygen atoms, and the results are shown in Fig. 4.

The very intriguing color of the crystals prompted us to record absorption spectra from the microcrystalline powder using an integrating Ulbricht sphere. The

Table 1: Crystallographic measurement and X-ray diffraction data collection for 6 .

\begin{tabular}{|c|c|}
\hline Formula & $\mathrm{C}_{24} \mathrm{H}_{13} \mathrm{~N}_{9} \mathrm{O}_{12} \cdot 1 / 2 \mathrm{C}_{7} \mathrm{H}_{8}$ \\
\hline$M_{\mathrm{r}}$ & 665.50 \\
\hline Crystal system & Monoclinic \\
\hline Measurement temperature, $\mathrm{K}$ & 293 \\
\hline Space group & $P 2_{1} / n$ \\
\hline$a, \AA$ & $8.24685(7)$ \\
\hline$b, \AA$ & $19.41735(17)$ \\
\hline$c, \AA$ & $18.48711(18)$ \\
\hline$\beta$, deg & 98.7823(9) \\
\hline$V, \AA^{3}$ & $2925.67(5)$ \\
\hline$z$ & 4 \\
\hline$D_{c}, \mathrm{~g} \mathrm{~cm}^{-3}$ & 1.511 \\
\hline Crystal color & Brown \\
\hline Crystal size, $\mathrm{mm}^{3}$ & $0.28 \times 0.16 \times 0.13$ \\
\hline$\lambda\left(\mathrm{Cu} K_{\alpha}\right), \AA$ & 1.54184 \\
\hline No. of refl. measured/unique & $18807 / 5360$ \\
\hline No. of observed refl. $\left[F^{2}>2 \sigma F^{2}\right]$ & 4832 \\
\hline No. of parameters refined & 422 \\
\hline$R 1 / w R 2\left[F^{2}>2 \sigma\left(F^{2}\right)\right]^{\mathrm{a}, \mathrm{b}}$ & $0.0581 / 0.1662$ \\
\hline$R 1 / w R 2$ (all refl.) & $0.0624 / 0.1711$ \\
\hline Goodness of fit (all refl.)c & 1.063 \\
\hline Residual charge density, e $\AA^{-3}$ & $-0.493 /+0.644$ \\
\hline
\end{tabular}

a $R 1=\Sigma|| F_{0}|-| F_{c}|| / \Sigma\left|F_{0}\right|$.

${ }^{\mathrm{b}} W R 2=\left[\Sigma W\left(F_{\mathrm{o}}^{2}-F_{\mathrm{c}}{ }^{2}\right)^{2} / \Sigma w\left(F_{\mathrm{o}}^{2}\right)^{2}\right]^{1 / 2}, W=\left[\sigma^{2}\left(F_{\mathrm{o}}^{2}\right)+(0.0861 P)^{2}+1.5963 P\right]^{-1}$, where $P=\left(\operatorname{Max}\left(F_{0}^{2}, 0\right)+2 F_{\mathrm{c}}^{2}\right) / 3$.

${ }^{\mathrm{G}} \mathrm{GoF}=S=\left[\Sigma w\left(F_{0}^{2}-F_{\mathrm{c}}^{2}\right)^{2} /\left(n_{\text {obs }}-n_{\text {param }}\right)\right]^{1 / 2}$, where $n_{\text {obs }}$ is the number of data and $n_{\text {param }}$ the number of refined parameters. 

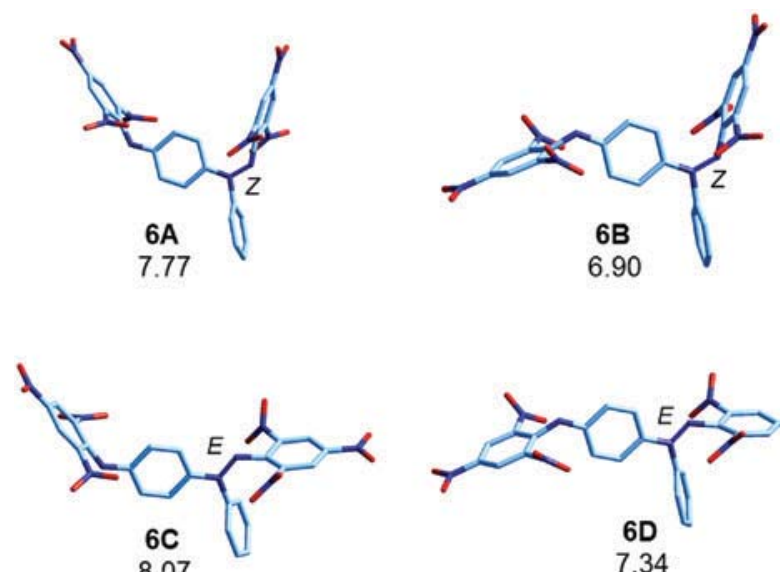

8.07
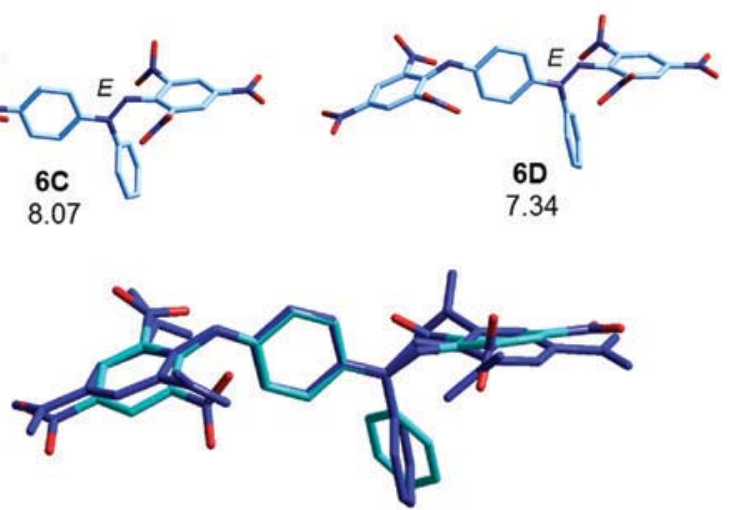

Fig. 3: Four different conformers of betaine 6 (PM3 calculation). The numbers represent the calculated ground-state dipole moments in Debye units. The conformers $6 \mathrm{~A}$ and $6 \mathrm{C}$ on the left have the picryl group in a syn orientation, while 6B and 6D are anti. Below is the computed structure 6D (in blue wireframe) overlayed over the crystal structure (shown with cyan carbon, blue nitrogen, and red oxygen atoms).

spectrum shown in Fig. 5 has a prominent maximum at $742 \mathrm{~nm}$ with several broad maxima in the ultraviolet region which is separated by a deep trough from the visible. The inset in Fig. 5 shows a photograph of the sample holder with microcrystals of $\mathbf{6}$ having metallic reflexes. Upon wiping with tissue paper, these ochre-copper-colored crystals leave deep blue traces, like a fountain pen ink.

In solution we recorded the spectra shown in Fig. 6. In anhydrous ethanol it is sparingly soluble under sonication, whereas in dry dichloromethane it is well soluble. The visible maximum in dichloromethane is now at $574 \mathrm{~nm}$. When a concentrated solution of 6 in dichloromethane is abruptly diluted into a large excess of dry $n$-heptane, a self-assembly process takes place which is accompanied by a red-shifted and broadened shoulder together with a baseline shift due to light scattering. Aggregates settle as a fine film on the quartz walls of the cuvette with $1 \mathrm{~cm}$ path length. There is only a slight hypsochromic shift with the increasing polarity of the solvent from dichloromethane to ethanol (negative solvatochromic effect) $[15,16]$.

We also recorded fluorescence spectra from the same solutions and the samples were non-emissive. The fact that fluorescence is totally quenched speaks for an

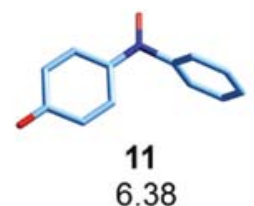

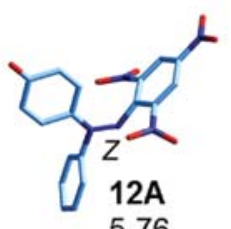

5.76

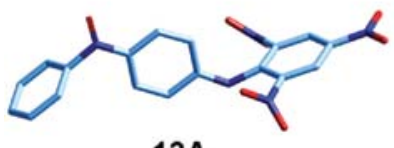

$13 \mathrm{~A}$ 10.39

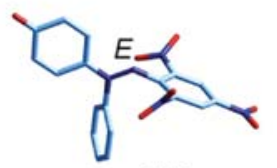

12B
Fig. 4: Calculated ground-state dipole moments (in Debye units) for the oxygen analogs 11, 12, and 13 of betaine 6 .

efficient internal conversion pathway as deactivation from the excited state.

\section{Conclusions}

The betainic structure proposed earlier for compound $\mathbf{6}$, which resulted from two molecules of 2,2-diphenyl-1-picrylhydrazyl and one molecule of $N$-methoxy-picramide

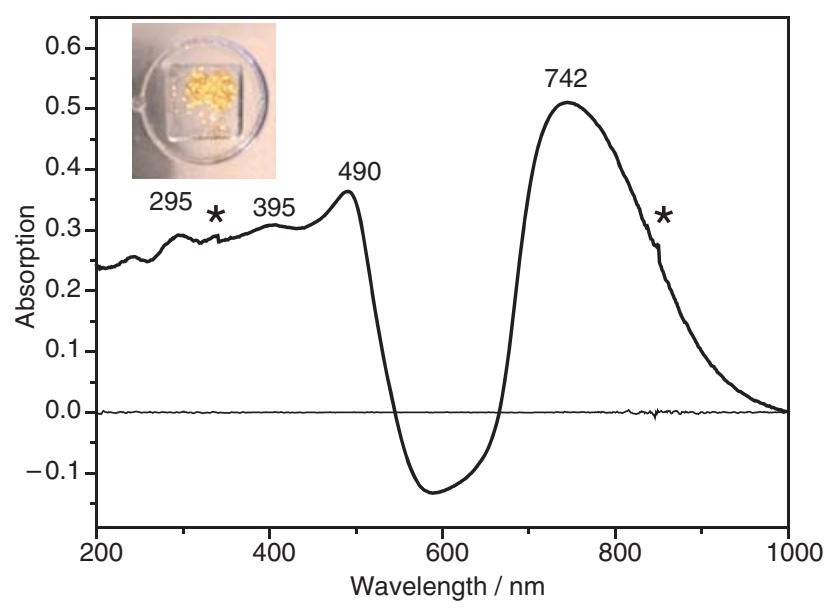

Fig. 5: Absorption spectra of microcrystals of 6 recorded in an integrated sphere. The thin horizontal line represents the spectrum recorded with the same instrument settings after emptying and cleaning the sample holder. Both traces have been baseline subtracted. The inset shows a photograph of the sample holder partially filled with the sample showing metallic reflexes. The asterisks mark spikes due to the change of the detector. 


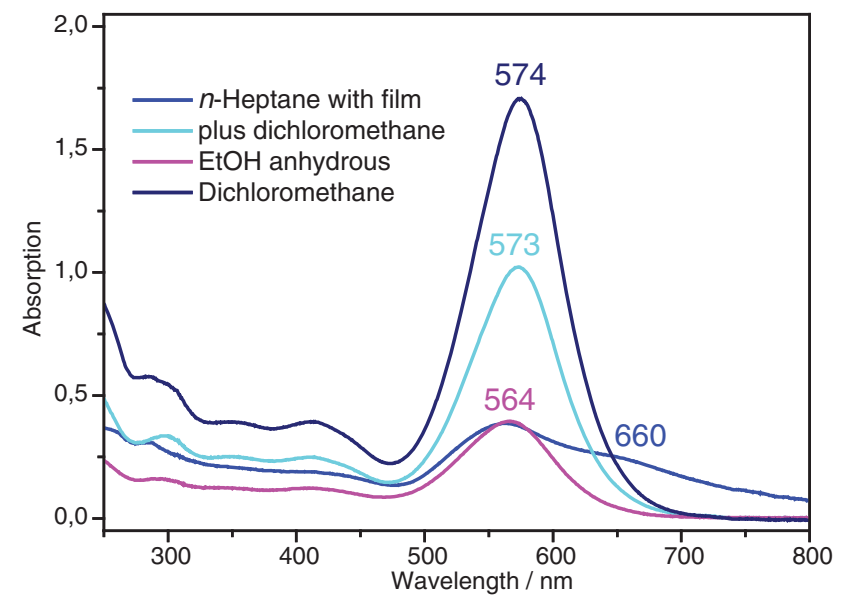

Fig. 6: Absorption spectra of crystals of betaine 6 dissolved in various solvents.

by elimination of the methoxy group, was confirmed by single-crystal X-ray diffractometry. The para-position of the anti-oriented phenyl group in DPPH becomes connected to the intermediate $N$-methoxy-aminyl free radical. As a result, the central phenylene group in $\mathbf{6}$ acquires a quinonoid structure with two clearly evidenced shorter bonds, indicating the predominant contribution of the resonance structure $\mathbf{6 a}$ over the aromatic structure $\mathbf{6 b}$. Intermolecular $\pi-\pi$ interactions account for relatively short distances between picryl groups as shown in Fig. 7. The quinonoid structure accounts for the deep blue color of compound 6.

An analogy between picramido groups and oxygen atoms with similar electronegativities allows comparisons between DPPH and $N, N$-diphenylnitroxide 10, or between the betaine 6 and the nitrone derived from

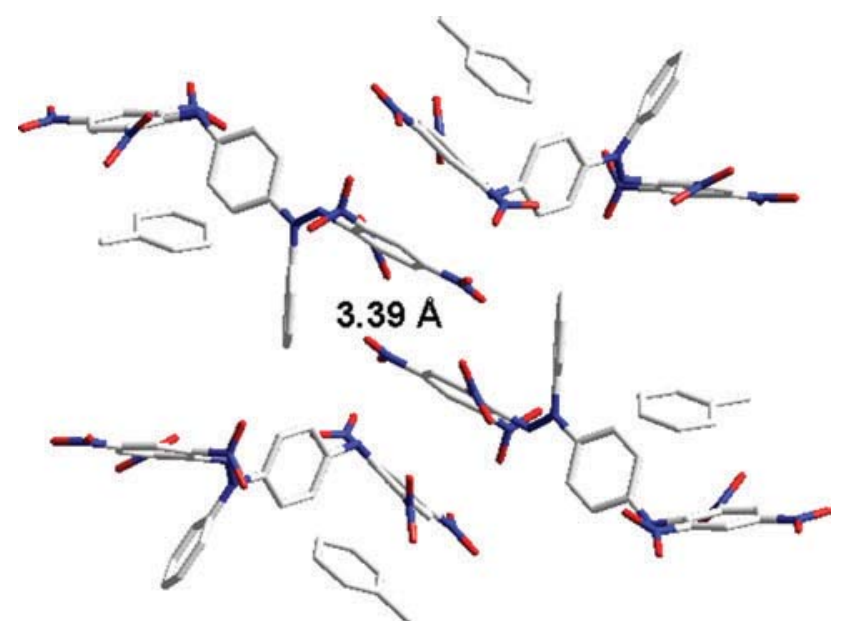

Fig. 7: Packing of the betainic molecules 6 in the crystal with disordered solvent molecules (toluene). Hydrogen atoms are not shown.
$N$-phenyl-para-quinoneoxime (11). Although picryl and 2,6-dinitrophenyl groups have lower electronegativities than oxygen atoms, they compensate additionally for the stabilization of free radicals by steric shielding.

\section{Experimental section}

The intensity data were collected at $293 \mathrm{~K}$ on a Rigaku Oxford Diffraction SuperNova diffractometer using $\mathrm{CuK}_{\alpha}$ radiation $(\lambda=1.54184 \AA)$. Data collection, cell refinement and data reduction were performed with CrysAlisPro (Rigaku Oxford Diffraction). Using OLEX2 [17] the structure was solved with the Superflip structure solution program [18-20], and SHELXL [21] was used for full matrix leastsquares refinement. Reflections were merged by SHELXL according to the crystal class for the calculation of statistics and refinement. Empirical absorption correction was performed using spherical harmonics, implemented in the SCALE3 ABSPACK scaling algorithm.

CCDC 1492196 contains the supplementary crystallographic data for this paper. These data can be obtained free of charge from The Cambridge Crystallographic Data Centre via www.ccdc.cam.ac.uk/data_request/cif.

Compound 6 was obtained as indicated previously [5], and it co-crystallized with a disordered toluene solvent molecule lying on a center of symmetry. The hydrogen atoms were all found experimentally, except for the disordered toluene solvent where they were introduced in calculated positions, and they were refined as riding atoms with their $U_{\text {iso }}$ parameters fixed to $1.2 U_{\text {eq }}$ (parent atom) for the aromatics and to $1.5 U_{\text {eq }}$ (parent atom) for the methyl of the toluene.

Semi-empirical calculations were performed at the PM3 level using the HYPERCHEM ${ }^{\circledR}$ program package [14].

Absorption spectra were measured from microcrystals of 6 in an integrating sphere with a JASCO V-670 Spectrophotometer. Samples in solution were measured in rectangular Hellma fluorescence cuvettes with $1 \mathrm{~cm}$ path length on a Shimadzu UV-2401 (PC) instrument. Fluorescence spectra were recorded on a JASCO fluorimeter.

\section{References}

[1] S. Goldschmidt, K. Renn, Ber. Dtsch. Chem. Ges. 1922, 55, 628.

[2] D. E. Williams, J. Am. Chem. Soc. 1967, 89, 4280.

[3] C. T. Kiers, J. L. De Boer, R. Olthof, A. L. Spek, Acta Crystallogr. 1976, B32, 2297.

[4] D. Žilić, D. Pajić, M. Jurić, K. Molčanov, B. Rakvin, P. Planinić, K. Zadro, J. Magn. Reson. 2010, 207, 34. 
[5] T. Constantinescu, M. T. Caproiu, N. Zarna, A. Caragheorgheopol, H. Caldararu, G. Stanciuc, M. Radu, V. Badescu, A. T. Balaban, New J. Chem. 1997, 21, 575.

[6] G. Stanciuc, M. T. Caproiu, A. Caragheorgheopol, H. Caldararu, A. T. Balaban, R. I. Walter, J. Magn. Reson. 1987, 75, 63.

[7] E. N. Hristea, M. T. Caproiu, G. Pencu, M. Hillebrand, T. Constantinescu, A. T. Balaban, Int. J. Mol. Sci. 2006, 7, 130.

[8] A. T. Balaban, Rev. Roum. Chim. 1971, 16, 725, and further references cited therein.

[9] H. G. Viehe, R. Mrenyi, L. Stella, Z. Janousek, Angew. Chem. Int. Ed. Engl. 1979, 18, 917.

[10] R. W. Baldock, P. Hudson, A. R. Katritzky, F. Soti, J. Chem. Soc. Perkin Trans. I 1974, 1422.

[11] J. W. Linnett, J. Am. Chem. Soc. 1961, 83, 2643.

[12] J. W. Linnett, The Electronic Structure of Molecules, A New Approach, 2nd edition, Methuen, London, 1974, chapter 7.
[13] M. T. Caproiu, M. Elian, N. Grecu, N. Negoita, A. T. Balaban, J. Chem. Soc. Perkin Trans. I/ 1983, 591.

[14] HYPERCHEM ${ }^{\circledast}$ (release 8), Hypercube Inc., Gainesville, FL (USA) 2007; www.hyper.com (accessed November 2016).

[15] C. Reichardt, Solvents and Solvent Effects in Organic Chemistry, 4th edition, Wiley-VCH, Weinheim, 2011.

[16] V. G. Machado, R. I. Stockand, C. Reichardt, Chem. Rev. 2014, $114,10429$.

[17] O. V. Dolomanov, L. J. Bourhis, R. J. Gildea, J. A. K. Howard, H. Puschmann, J. Appl. Crystallogr. 2009, 42, 339.

[18] L. Palatinus, G. Chapuis, J. Appl. Crystallogr. 2007, 40, 786.

[19] L. Palatinus, A. van der Lee, J. Appl. Crystallogr. 2008, 41, 975.

[20] L. Palatinus, S. J. Prathapa, S. van Smaalen, J. Appl. Crystallogr. 2012, 45, 575.

[21] G. M. Sheldrick, Acta Crystallogr. 2015, C71, 3. 